***To appear in The Blackwell Companion to Experimental Philosophy, Ed. by J. Systma and J.W.Buckwalter, Oxford: Blackwell***

\title{
Naturalistic Approaches to Creativity
}

\author{
Dustin Stokes (University of Utah) \\ Elliot Samuel Paul (Barnard College, Columbia University)
}

It is entirely obvious that creativity is important to human thought, action, and culture. A platitude, as we say. Nevertheless, the topic has received scant philosophical attention. And very little of this attention has been naturalistic in some clear sense, either informed by empirical data from the behavioural and brain sciences, or involving novel design and execution of experiments. So if there is an experimental philosophy of creativity, it would be reasonable to say it is still in seed form.

However, there is reason for optimism. First, there has been an increase in general philosophical attention to the topic. ${ }^{1}$ Second, the philosophical neglect of the topic is not mirrored in psychology, neuroscience, computer science, artificial intelligence research, and other related empirical disciplines. Indeed, there has been a surge of empirical work on the topic, largely prompted by an explicit prescription to research creativity delivered by J.P. Guilford in his 1950 presidential address to the American Psychological Association. ${ }^{2}$ Today, scientific work on creativity ranges in method from experimental surveys to brain scanning to evolutionary robotics. ${ }^{3}$ And philosophers are becoming increasingly mindful of the ways in which scientific findings might be relevant to their own investigations on a variety of topics including causation, perception, consciousness and morality. ${ }^{4}$ Creativity, it seems, is beginning to follow suit. 
In what follows, we offer a brief characterization of creativity $(\S 1)$ followed by a review of some of the reasons people have been skeptical about the possibility of explaining creativity (§2). We then survey some of the recent work on creativity that is naturalistic in the sense that it presumes creativity is natural (as opposed to magical, occult, or supernatural) and is therefore amenable to scientific inquiry. This work is divided into two categories. The broader category is empirical philosophy, which draws on empirical research while addressing questions that have traditionally been regarded as philosophical $(\S 3)$. The second category is experimental philosophy, a special branch of empirical philosophy in which experiments are designed (by philosophers) with the explicit purpose of addressing philosophical questions (§4). ${ }^{5}$ This categorization is admittedly somewhat artificial, but it is a familiar one in the prevailing division of intellectual labor, and it will be a useful organizational tool for this chapter.

\section{A brief characterization of creativity}

The adjective 'creative' can be applied to persons, processes, or products. Researchers typically define creativity primarily with reference to the creative product. There is a near consensus among creativity researchers that in order for a product to be creative, it must satisfy at least two conditions. Most obviously, it has to be new or original. But novelty is not sufficient because, something could be new but worthless, and 'creative' is a term of praise which we tend not to accord to worthless things. Thus, according to what has become the standard definition in psychology, a creative product must not only be novel but also useful, effective, appropriate or, more generally, valuable in some way. ${ }^{6}$ The relevant kind of value varies between creative domains: various aesthetic values in the arts, epistemic and explanatory values in the sciences, etc. Given the definition of a product as creative when it is valuable and new, 
one might then define creative persons and creative processes as those which produce, or have a propensity to produce, things that are valuable and new.

Novelty is a relational property. As Margaret Boden (1990) notes, something can be new to the person who created it (psychologically novel) without being new to all of human history (historically novel). Boden accordingly distinguishes between 'psychological creativity' and 'historical creativity'. Clearly, historical creativity is the more striking phenomenon. What puts Picasso or Bach or Einstein or Hawking in the category of "Genius" is, perhaps among other things, that they did radically new things. And indeed this contributes to the daunting feeling that creativity may be inexplicable. But it may be that some of the features that make something radically novel (or historically creative, whatever other necessary conditions satisfied) are sociological, historical, or otherwise contextual. And so explanations that attempt to identify the fundamental psychological mechanisms responsible for creativity may better focus on more mundane instances of the phenomenon and so, accordingly, focus on actions and thoughts that are at least psychologically novel. Boden's distinction is especially useful in this regard, since it potentially identifies a more scientifically tractable subset of the target phenomenon.

Beyond the claim that creative products are (at least psychologically) novel and valuable in some way, extant analyses vary widely. Some claim that creative products must be unpredictable or surprising. ${ }^{8}$ Others that creativity, as an achievement, requires agency or intentional action; accidental creativity is thus a conceptual impossibility. ${ }^{9}$ Others argue for negative conditions, for example that creativity can never be malevolent. ${ }^{10}$ These additional candidates will not be analyzed here, but some of them will surface below in discussions of particular explanations. 


\section{Skepticism about explaining creativity}

There are traditional and contemporary skeptical challenges to the project of explaining how creativity happens. The skeptics are many, so we select and briefly discuss only those that are most relevant to the explanations offered below in $\S 3$ and $\S 4$.

One general cluster of views - call it inspirationalism — conceives of creativity as resulting from divine inspiration or madness. Both views are often attributed to Plato; ${ }^{11}$ the latter is attributed to Schopenhauer. ${ }^{12}$ What unifies the views is that they maintain that creative persons are patients, not agents, of creativity. These persons are inspired, and because the nature of the inspiration is supernatural or extremely abnormal, their action is out of the scope of (scientific) explanation. Peter Kivy seems to express sympathy for this view when he says that "Bright ideas just 'happen' to people...That was Plato's (or Socrates') discovery. Insight is a kind of 'infectious disease' that one succumbs to" (Kivy 2001: 11).

Inspirationalism might be partly motivated by observing a more general phenomenon, namely, the "A-ha moment." Sometimes interesting or clever or novel thoughts "just come to us" as we say. This is well-evidenced both by famous anecdotes about Eureka moments and reflection on one's minor cognitive breakthroughs ("that's how I crack an egg with one hand..."). The phenomenology here suggests both that one is not deliberately thinking the thoughts - they just happen — and, accordingly, one is not really responsible for such thoughts. Add to this: when an a-ha moment occurs, it is often in a context where one is focused on entirely different matters, or perhaps daydreaming as Kekulé was allegedly doing when he envisioned the ring-like structure of the benzene molecule. Thus great ideas sometimes come only after a period of incubation. ${ }^{13}$ Cast in this light, inspirationalism enjoys some plausibility: how can thoughts that appear to come out of nowhere be explained? 
Another pair of reasons for skepticism concern the variety and complexity of creativity. We find creativity not only in art, but in science, theorizing of any sort, engineering, business, medicine, sport, gaming, and so on. At least two worries may be developed accordingly. First, given the complexity of any one of these individual domains, one might worry that there are simply too many variables to allow for a clear explanation. Art provides a paradigmatic example. Consider an artwork that you judge to be masterful (a painting, a composition, a film). Now imagine attempting to describe or identify all the reasons for which you think it is masterful. Take as much time as you like but, the skeptic will urge, any long description you construct will invariably strike you as woefully incomplete by comparison to the artwork, and the experience thereof. So, if the creative achievements of artists, in all of their complexity, cannot even be adequately described, we have little reason to think that such achievements can be explained. ${ }^{14}$ The second worry concerns generalizability. Even supposing that one could explain the creative achievement of some artistic master, any such explanation will have to be so specific that it will fail to generalize to artistic creativity, or creativity in other domains like science or gaming or whatever. In short, given the variety of creativity (and the complexity of the varied creative achievements), identifying a general explanation, in the form of a set of cognitive and behavioral features, may seem entirely improbable.

Yet another source of skepticism is focused on the surprising novelty involved in creativity. Carl Hausman $(1976,1979,1984)$, for example, argues that if a product is creative, it must be metaphysically novel (he says 'genuinely novel') in the sense that it cannot be predicted from, or explained by, prior events - not even in principle. Creativity is therefore incompatible with causal determination and causal explanation: "A causal view of explanation sets a framework for ways of denying that there is anything new under the sun" (Hausman, 1984, p. 
ix). If something can be explained by prior causes, it is not metaphysically novel, and is therefore, in Hausman's view, not truly creative.

These are four general reasons (or sets of reasons) for which many have doubted that creativity can be explained. There are others, and some of them will be mentioned below, counterposed to the explanations that attempt to overcome them.

\section{Empirical Philosophy (and Relevant Scientific Research)}

Understanding 'empirical philosophy' rather broadly, this section discusses a range of recent research on creativity, from disciplines including cognitive psychology, computational theory, evolutionary theory, and naturalistic philosophy.

\subsection{Compatiblism}

In response to Hausman's skepticism, Maria Kronfeldner (2009) argues that creativity is compatible with causal determination and therefore with naturalistic explanation. The first point to notice here is that determinism does not preclude novelty or change. Determinism says the emergence of new kinds of things can at least in principle be predicted in advance, but something new still will be added to the world when the prediction comes to pass. Of course, not all novelty instantiates creativity. The question is whether the kind of novelty involved in creativity must be metaphysical novelty, which is by definition incompatible with causal determination. This is doubtful. Notice that, by definition, metaphysical novelty defies natural laws. The production of something metaphysically novel would therefore require supernatural powers. Traditional Western religions conceive of God as performing the miracle of creation $e x$ nihilo. But are we positing a miracle every time we describe a human artifact as creative? Surely not. As noted above, human creativity is manifest in things that are new to the 
agent producing them or new to human history, but both of those kinds of novelty (psychological and historical) are perfectly compatible with causal determination. As Kronfeldner explains, creativity does not preclude causes in general; it only precludes certain kinds of causes. A creative product, she argues, must be original - which means that it cannot be produced through a process of copying something prior. And it must be spontaneous (not produced through a routine or mechanical procedure) - which means that it is to some extent independent of the agent's intentional control and previously acquired knowledge. The causes of something creative cannot simply be a matter of copying or following a routine. But there may be causes nonetheless, which cognitive science can investigate, at least in principle, and indeed, it has begun to do so in practice. We consider some of those efforts now.

\subsection{Cognitivist explanations}

Of the broadly cognitivist explanations of creativity, two extremes can be identified. A unique mechanism explanation posits some creativity-specific cognitive mechanism/s. Any such mechanism could be modular or functionally independent, but what is central is that its primary cognitive role is to produce creative thought. By contrast, a re-use explanation identifies more fundamental cognitive mechanisms and attempts to show how their use, in relevant contexts can generate creative thought. ${ }^{15}$

The Darwinian model of psychologist Donald T. Campbell, recently advanced by Dean Simonton, provides an example of a special mechanism explanation of creativity (Campbell 1960, 1965; Simonton 1999). The model has two parts. First, there must be a variation-generator in the cognitive system: a mechanism that, by analogy with Darwinian evolution and genetic mutation and variation, produces variations on ideas and concepts. Second, there must be a selection-mechanism. This mechanism, by analogy with the role of natural or sexual selection in 
biological evolution, selects ideas to be retained and stored by memory, refined and elaborated in ongoing thought, and/or passed on through communication. The selection of ideas might be performed by more general cognitive mechanisms. But the variation-generator, as typically presented by the Darwinian model, is plausibly a creativity specific mechanism. ${ }^{16}$

The Creative Cognition Approach provides an example of a re-use explanation. That research program, concentrated heavily in the 1990s, involved both a descriptive and a normative element. Descriptively, these researchers "conceive of creativity not as a single unitary process but as a product of many types of mental process, each of which helps to set the stage for creative insight and discovery" (Finke et al 1992: 2; See also Smith et al. 1995; Ward et al. 1999). These more basic mental processes include imagery, categorization, and problem solving, each of which have been extensively studied (and much more than creativity as such). And these basic processes, and others, are invoked in two distinct stages: an idea generation stage and an exploration stage where that idea is considered, elaborated, revised and accepted/rejected. This is the Geneplore model. As a normative matter, these researchers aim to identify strategies and principles that optimize potential for creative thought (while explicitly denying that this will amount to identification of creativity guaranteeing algorithms). ${ }^{17}$

Both types of explanation are vulnerable to challenge. The special mechanism explanation, taking the Darwinian model as the example, is less parsimonious than the alternative. Indeed, one might further worry about the empirical plausibility of humans evolving or developing a creativity-specific mechanism. ${ }^{18}$

The Geneplore model can be presented with a dilemma. On the one hand, identification of the particular mechanisms responsible for a creative achievement (on this model: both the generation and the exploration of the relevant idea/s) would be so specific as to fail to generalize 
to any (or many) other creative achievements. This would amount to a backward looking causal description, but not an explanation. On the other hand, any attempts to identify general processes or mechanisms common to all creative achievement is likely to be so broad as to be trivial (e.g. all creativity involves thought or skill). The consequence is the same: no robust explanation of the phenomenon. David Novitz (2003) offers a version of this worry, also claiming that because creative achievements can be performed in a multitude of ways, they cannot be explained in terms of a single mechanism or a set of principles.

Recent work (some of it done by advocates of the Geneplore model) suggests an explanation of the A-ha moment, and provides a possible counterexample to this last set of worries. Although it is implausible that all creative thought and action involves an a-ha moment, much of it does. And moreover, this common feature of the phenomenon is one of the very ones that has motivated claims that creativity is inexplicable. Various researchers describe the a-ha phenomenon in terms of incubation. The idea should be familiar. Imagine you are working on a puzzle of some kind, and you get stuck. What do you do? Recent research suggests a prescription each for what you should do and what you should not do. First, you should not continue to struggle with the puzzle, once you are stuck. This is what Smith and Blankenship $(1989 ; 1991)$ call fixating. In their experiments, subjects that remain fixated on incorrect strategies or solutions to a problem, and who continue to attempt solution of the same problem, will do comparatively poorly. So what should you do? Forget it, Smith and Blankenship suggest. Subjects in an opposite experimental group take time away from the target problem (often with a distractor task) and then presumably temporarily forget the problem (and accordingly, the fixated incorrect solution or strategy). These subjects do significantly better than the fixated subjects upon returning to the very same problem. ${ }^{19}$ 
These researchers call this an incubation effect. What explains it? Dustin Stokes (2007) argues that incubated cognition is well within the scope of naturalistic explanation. Since at least the middle of the 20th century, an uncontroversial fact in neuroscience is that brains are plastic: connectivity between neural cells changes as an individual moves around, engages with, and perceives her environment. Hebb (1949) offers an instructive way to think of this. ${ }^{20}$ Neural cells connect (and their connectivity changes in strength) according to simple spatial and temporal principles. "Cells that fire together", nearly synchronous and spatially proximal, "wire together". And when these connections or "assemblies" form, activity in one part of the assembly will facilitate activity in other parts. This assembling of brain networking takes place nearly all the time. And, importantly, activity in an assembly often continues or "reverberates" after presentation of the stimulus, and this creates, strengthens, or (at that time) activates the assembly. This continued (sub-personal) activation can result in new or strengthened connections between cells and other assemblies (bear in mind that the brain is massively networked). Now suppose that one is working on a problem of some kind (from banal—how do I get from there to here in less than 10 minutes? - to momentous-what is the structure of the benzene molecule?). Attention to this problem will activate and strengthen neural connections, and likely create new ones too. Then one gives up, or gets distracted, or has a nap. In the terms of much of classical creativity literature, one lets one's ideas (on that task) incubate. And what follows is supposed to be magical: one returns to the problem and...A-ha!...the solution is suddenly clear. Stokes's explanation claims that, assuming that thoughts are correlated with neural activity, and granting these sub-personal effects of attention on plastic neural networking, the a-ha insight is readily explicable. The new thought is the result of (or supervenes on, or just is) the activation of new or newly strengthened connections (which themselves took place during the incubation period, 
while one was occupied with something other than the target problem). Explanation of any particular a-ha insight would require a complex story — and one that goes beyond current neuroscientific understanding and technology_-but basic principles for such a naturalistic explanation are in place.

This explanation suggests a counter to the worry about generalizability. A-ha moments are common, and occur in a variety of cognitive and problem solving domains. A complete explanation of any one instance of creativity will accordingly require specification of details specific to the domain. However, the principles concerning attention, fixation, and neural connectivity are sufficiently general to explain the common phenomenon of incubation and insight. This is a parsimonious, re-use type of explanation of a traditionally elusive feature of creativity.

\subsection{Imagination and evolution}

In ordinary language, the terms 'creative' and 'imaginative', and their cognates, are often used interchangeably. A moment's reflection should, however, reveal that the two sets of terms

come apart in their appropriate application. ${ }^{21}$ Nonetheless, what's right here is that there is some deep connection between imagination and creativity, and this observation is made in both ancient and modern philosophy. Perhaps most famously, in his Critique of Judgment, Kant argued that when imagination is used in the right way (free from the constraints imposed by conceptual understanding), it amounts to richly creative thought. What's lacking here, both in the folk story and the traditional philosophical story, is any rich explanation for why imagination is especially important for creative achievement.

Recent work by Gaut $(2003 ; 2009 ; 2010)$ and Stokes $(2014)$ provide, on both conceptual and empirical grounds, an analysis of the role of imagination in creativity. Gaut maintains that 
creative achievement must be novel and valuable. Additionally, it cannot result from chance; as Gaut puts it, creative production involves "flair" on the part of the creator. He then argues that imagination is the "vehicle" or medium for active creativity. Why? Imagination, since detached from truth and action, while still being potentially under immediate and voluntary control, allows one to "try out" various moves or strategies in attempting to solve a problem (one of Gaut's favored examples here is a chess master). This last claim is supported conceptually. Moore's paradox says that an assertion "I believe that P, but not P" is irrational. Analogously, to assert "I intend to do Q, but I won't do Q when given the opportunity” seems equally problematic. But there is no relevant analogue for imagination; neither of the following assertions are troublesome: "I imagine that P, but P is false"; "I imagine doing Q, but I will never do Q". So, because imagination (as such) lacks these representational and action-coupled functions, it is especially suitable for active, creative problem solving. ${ }^{22}$

Stokes (2014) also maintains that imagination may be unnecessary for creativity, while claiming, also like Gaut, that it is especially well suited - given its freedom from truth and action and its voluntariness - to enable creative thought. The claim here partly concerns rich creative achievement, which apparently requires mental states or processes that have no inherent function to accurately track or represent some part(s) of the world ("non truth-bound" states or processes). But Stokes argues further that this cognitive freedom is needed for more banal or "minimal" everyday instances of creativity, which involve P-novelty and are the non-accidental result of the agency of the creator. ${ }^{23}$ Various experiments on cross-category task performance and learning in children and adults - e.g. where subjects must apply the concepts HOUSE and PERSON in agent-relative novel ways in order to draw a humanized house, or where subjects must abstract from literal meaning and referential linguistic strategies in order to learn figurative language- 
suggest that basic instances of effortful, novel cognition are not achieved by rote learning. ${ }^{24}$ Instead, these achievements require some kind of cognitive manipulation of the information from the relevant conceptual space(s), often using it in cross-categorical ways (e.g. giving a house window-eyes or a door-mouth). These achievements are not richly creative, but they lie on the extreme end of a spectrum, opposite the end of the spectrum where creative achievements of artistic and scientific geniuses are plotted. What unifies the achievements on this spectrum is that they require for their performance thinking in non truth-bound ways. And many (but not all or only) of the creative achievements on the genius end of the spectrum involve an enriched cognitive manipulation role, where voluntary non truth-bound states interact with some combination of affective, motivational, inferential, and free associative capacities. Stokes then argues that because imagination enjoys two characteristic features - it is playful (as identified by Gaut and others) and it is workful (it may figure in inference, be used to test or consider modal truths, and so on $)^{25}$-imagination plausibly best serves the cognitive manipulation role. Finally, on a liberal account of the imagination, the free-association that is supposed to characterize a-ha moments of insight, just is a kind of imaginative activity. ${ }^{26}$ Or more conservatively, imagination is the deliberate activity that follows the moment/s of insight, where the ideas that result from non-deliberate free-association are considered and revised as part of the overall creative process. (Contrary to what some romantic descriptions suggest, it is the rare case where the a-ha moment is accepted and applied straightforwardly to the task or problem. Typically, some additional cognitive work must be done with the insight.) This merges analyses of Gaut's passive and active creativity, suggesting that there is an important role for imagination in any such process.

Peter Carruthers (2002; 2005; see also Picciuto and Carruthers 2014) argues for an evolutionary connection between imagination and creativity. Carruthers' general line of thought 
is this. We have good evidence that creative behaviour emerged on a large scale, and across disparate populations of the human species, approximately 40,000 years ago (where Homo sapiens sapiens had developed to our current anatomical form approximately 100,000 years ago). ${ }^{27}$ We also know that creativity, again understood minimally, is a pervasive human phenomenon, ranging in degree from the banal to the genius. Given this ubiquity and general considerations of parsimony, an explanation that attributes no particularly special or exotic cognitive faculties is to be preferred. Many extant explanations fail, Carruthers argues, by one or more of these criteria. For example, various language based explanations apparently must commit to implausible claims about the evolution of language (e.g. that it emerged when creativity did, and coincidentally across the widely, geographically dispersed groups of the human species), and further lack a plausible story about how the relevant faculties are acquired or transmitted. ${ }^{28}$ Carruthers argues instead that imagination is plausibly the relevant cognitive mechanism. We know that imagination develops in all normal human children in the form of pretend play. And in adults, it presents an appropriate mechanism — whether in the form of mere supposition or some richer, more engaged imagining — for generating and then exploring ideas (as per the Geneplore model). Pretend play in children thus plausibly performs the evolutionary function for practicing adult creative thought and behavior. Furthermore, this mechanism may have been selected for-either given environmental or sexual selection pressures, or bothbetween the c.100,000ya and c.40,000ya gap. This explanation thus fits an orthodox evolutionary timeline for the human species, and commits only to cognitive mechanisms that are likely byproducts of other capacities: imagery comes with vision and propositional imagination and supposing comes with the development of language..$^{29}$ 


\section{X-Phi: Philosophers in the lab}

In this section we consider experimental philosophy, where experiments are conducted with the express purpose of addressing philosophical questions. Very little of this work has been done in creativity research, so here we offer a brief discussion of some work in artificial intelligence and artificial life research that best falls under the narrow x-phi category.

A number of experimental research programs in cognitive science reflect the important theoretical contributions of Maggie Boden (1990/2004). Boden's work, important for many reasons, cuts against the grain of common, skeptical thinking about computers and creativity. That common skepticism maintained, crudely, that "Computers can never be creative, since they just run their programs. And accordingly, computational methods and technologies are likely to teach us little if anything about human creativity." ${ }^{30}$ One of Boden's clear contributions is to deny that the second claim follows from the first. So, just as computers may provide informative models of the mind, without being minds, they might provide ways of modelling human creativity without being creative. ${ }^{31}$ For example, Boden characterizes the surprise element of creative achievement in terms of whether an act accords with versus deviates from the generative rules within a domain. Boden argues that creativity involves an act that one could not perform relative to those computational rules, and it is the breaking of some of these rules that explains our surprise at the achievement. Simply, we didn't think that could be done. There is a great deal more to be said here, but the basic lesson is this: computational technologies and concepts do offer novel ways to analyze basic folk intuitions about creativity, in this case, about surprise and unpredictability. This lesson extends to the two cases we briefly discuss now.

Could something produced by a computer be new and aesthetically interesting? For decades, David Cope's Experiments in Musical Intelligence (EMI) have been using automated 
computational technologies to compose music, and with great success (Cope 1991; 2001). Cope's methods have evolved over this time, but the basic platform remains the same: the computer (his algorithmic composer goes by "Emmy") combs many pieces of music, identifying and gleaning patterns at varying levels of fineness of grain. As Hofstadter (1995) describes it, given a set of inputs of, say, Chopin piano concertos, Emmy will construct new pieces in a way constrained by local flow-pattern of a voice (e.g. a piano) in relation to the input pieces and by the global positioning of voice fragments by comparison to input pieces. Hofstadter analogizes the first to a syntactic or formal constraint and the second to a semantic or content constraint. These constraints are then nuanced by additional programming, resulting in sensitivity to musical features like tension-resolution and composer-specific signatures. Taken together, and given a multitude of input pieces, Emmy abstracts and constructs a new piece. These pieces range from simple melodies to full-length symphonies. Remarkably, the pieces are often unmistakably styled — for example in the style of Brahms or Bach—while being novel. Moreover, when played side-by-side with human-composed pieces, listeners often cannot discern the computercomposed from the human-composed pieces. ${ }^{32}$ Finally, some of these compositions are actually very good! But don't take our word for it, you can find recordings with names like The Well Programmed Clavier and Beethoven's Symphony No 10 for purchase online.

Cope's work is theoretically significant in (at least) two ways. First, it offers a plausible counterexamples to the claim that the output of a program could be new and aesthetically valuable (and hence 'creative' by the standard definition. Notice, however, that this point about the creative product leaves open the question about the creative agent: exactly who or what is creative in this case - the program (Emmy), the programmer (Cope), or some kind of collective agent comprising both? If Emmy is not to be deemed a creator here, why not? What capacities 
are required for genuine creative agency - consciousness, intentionality, emotion, or other? - and which of these does Emmy lack and which does she possess? A second point of significance, then, is this: Cope's work provides rich and detailed case studies for exploring these kinds of questions.

Another set of recent research employs the techniques of artificial life and evolutionary robotics (ER). Research in this field is often broadly distinguished from research in more traditional artificial intelligence by employing a bottom up engineering strategy. AI researchers in the classical tradition typically program a system by fitting it with a store of information and a finite set of rules that constrain how the system manipulates input, computes over information stored, and delivers output. By contrast, connectionist systems (sometimes called artificial neural networks or $A N N \mathrm{~s}$ ), involve no explicitly programmed rules, but instead a learning algorithm that makes small adjustment to the system's connection weights and in a way that gradually (in the good cases) hones in on successful task performance (e.g. correct input-output pairings). Artificial life research, often done only in simulation, employs this latter kind of strategy, only over a larger scale: involving hundreds and sometimes thousands of "agents" in a population. These agents are typically identified with a distinctive ANN, and the entire population is subject to fitness functions. Agents are further subject to mutation and genetic crossover, and a Genetic Algorithm selects fit agents to populate later generations. This basic procedure is then cycled hundreds or thousands of times, where task performance in these agents is thus evolved rather than programmed.

In a recent set of studies, researchers used a very simple ER platform to evolve drawing behavior, and to analyze questions and concepts of creativity (Bird and Stokes 2006, 2007; Stokes and Bird 2008). Simulated agents in this research were modelled on a basic Khepera 
differential wheeled robot, with the addition of a mechanism for raising and lowering a linedrawer. These ANNs were very simple: seven sensors (six infrared and one line detector) and six motor neurons (two left wheel motor neurons, two right wheel motor neurons, two pen motor neurons). Each sensor connects to every motor neuron, making 42 total connections in the network; and in each sensory-motor cycle, the most strongly activated neuron moves the relevant motor. The ambitious motivation here was to evolve rather than program drawing, and so the agents were constrained by very general fitness functions: an agent lost fitness for crashing into a boundary wall, and gained fitness for pen sensor-line sensor correlations (e.g. it would gain fitness if when it sensed a line directly below, it raised its pen; and vice versa). Gradually, over 100s of generations, some very simple but nonetheless interesting behaviors emerged: for example, after 500 generations, a high fitness agent learned to maximize fitness by first drawing one continuous line around the rectangular area boundary and then, on a second pass, sweeping left and right over that line and gaining fitness for repeated line sensor-pen sensor correlation changes (i.e. making a new line when left of the boundary-following line, raising the pen when over that line, making a new line when right of the boundary-following line, and so on).

The resulting image is not much to look at, but Stokes and Bird (2006) argue that it (and many other results from these experiments) provides a novel empirical challenge to a traditional assumption about creativity, namely, that creativity is thwarted (if not precluded) by constraints. The motivation for this claim seems to be something like the following line of reasoning. Creative things are unpredictable. And if something is unpredictable, then it must result from constraint-free processes. So, creativity results from constraint-free processes. One may have doubts about the first premise, but grant it. And indeed one can imagine, from the armchair, plausible counterexamples to the second premise. The research in question gives an 
experimentally grounded reason to doubt the second general premise. The artificial agents in these experiments are highly constrained — by fitness functions, by their simple environment and simple sensorimotor structures. And while their behaviors may fall well short of being creative, they are, many of them, unpredictable in a deep way. Like Cope's research, these results also provide an interesting set of studies for exploring philosophical questions about novelty, agency, and other potential features of creativity. ${ }^{33}$

\section{Conclusion}

In this chapter, we have argued against the claim that creativity cannot be understood naturalistically. Creativity is compatible with causes (even deterministic causes) which could in principle be discovered empirically. Even the Aha! Moment, which takes the creator by surprise, is amenable to scientific explanation, in terms of the cognitive and neurological processes that continue through period of incubation. Imagination is particularly well-suited to creative thinking because it is not bound to truth (as belief is) or to action (as intention is), and thus it affords the flexibility to produce and explore new ideas. Some researchers propose that our human capacity for imagination - which we exercise as children in pretend play - was selected for in evolutionary history precisely because it facilitated creativity, which confers major advantages in the competition to survive and attract mates. Recent artificial intelligence has produced artifacts that are creative, by the standard definition, challenging assumptions about what computers can do, and providing valuable case studies for theorizing about creativity. All of this work treats creativity as a natural phenomenon, and draws on and interacts with findings in cognitive science.

To date, very little of this work counts as experimental philosophy in the sense of involving experiments (conducted by philosophers) with the express purpose of addressing 
philosophical questions. Much of experimental philosophy has been concerned to identify and explore folk intuitions about philosophically significant concepts like knowledge, morality, free will, intention, and semantic reference. Creativity surely ranks among these in terms of its scope and importance, but to our knowledge, it has not been on the list. Experimental philosophers have often argued, based on their findings, that philosophers have been mistaken in their claims about the intuitions people have, and that intuitions can vary in surprising ways. It may be fruitful, then, to examine intuitions about creativity. Under what conditions do people judge a product to be creative? Do they do so when and only when they deem the product to be valuable and new, as the standard definition would have it? Under what conditions do people judge a person or process to be creative? How do these intuitions about creativity interact with intuitions about other phenomena, like intention, consciousness, emotion, etc.? Given the significance of creativity, this suggests a great space of opportunity for experimentally minded philosophers to break new ground.

Acknowledgements

Many thanks to both editors and two anonymous reviewers for helpful feedback. 


\section{References}

Anderson, M.L. 2010. "Neural Reuse: A Fundamental Organizational Principle of the Brain." Behavioral and Brain Sciences, 33 (4):245.

Asmis, E. 1992. "Plato on poetic creativity." in The Cambridge Companion to Plato, edited by Richard Kraut, 338-64. Cambridge: Cambridge University Press.

Barsalou, L. and Prinz, J. 1997. "Mundane Creativity in Perceptual Symbol Systems.” In Creative Thought: An Investigation of Conceptual Structures and Processes. Edited by T. Ward, S. Smith, and J. Vaid, 267-307. Washington, D.C., American Psychological Association.

Bergeron, V. 2007. "Anatomical and Functional Modularity in Cognitive Science:

Shifting the Focus." Philosophical Psychology, 20 (2):175 - 195.

Bickerton, D. 1995. Language and Human Behavior. Seattle: University of Washington Press.

Bird, J. and D. Stokes. 2006. "Evolving Minimally Creative Robots." Proceedings of The Third Joint Workshop on Computational Creativity, European Conference on Artificial Intelligence, 1-5. 2007. "Minimal Creativity, Evaluation, and Fractal Discrimination." Proceedings of the 4th International Joint Workshop on Computational Creativity, 121-8.

Boden, M. 1999. "Computer Models of Creativity." In Handbook of Creativity. Edited by R. Sternberg, 351-72. Cambridge: Cambridge University Press. 1990/2004. The Creative Mind, 2 nd Edn. London: Routledge. 2005. "Creativity" In The Routledge Companion to Aesthetics, $2^{\text {nd }}$ Edn. Edited by B.

Gaut and D. Lopes, 477-88. London: Routledge. 2014. "Creativity and Artificial Intelligence." In The Philosophy of Creativity, Edited by E.S. Paul and S.B. Kaufman, 224-44. New York: Oxford University Press.

Byrne, A. and Hilbert, D. 2003. "Color Realism and Color Science." Behavioral and Brain Sciences, 26: 1-44

Cacciari, C., Levorato, M., and Cicogna, P. 1997. "Imagination at Work: Conceptual and Linguistic Creativity in Children" In Creative Thought: An Investigation of Conceptual Structures and Processes. Edited by T. Ward, S. Smith, and J. Vaid, 179-208. Washington, D.C., American Psychological Association.

Campbell, D. 1960. "Blind variation and selective retention in creative thoughts as in other knowledge processes." Psychological Review, 67: 380-400.

1965. "Variation and selective retention in socio-cultural evolution." In Social Change in Developing Areas. Edited by H. Barringer, G. Blanksten, R. Mack, 19-49. Cambridge: Schenkman. 
Carruthers, P. 2002. "Human Creativity: Its Cognitive Basis, its Evolution, and its Connections with Childhood Pretence." British Journal for the Philosophy of Science, 53: 225-49. 2006. The Architecture of the Mind: Massive Modularity and the Flexibility of Thought. Oxford: Clarendon Press. 2007. "The creative action theory of creativity." In The Innate Mind, Vol. 3, Foundations and the Future. Edited by P. Carruthers, S. Laurence, and S. Stich, 254-71. Oxford: Oxford University Press.

2011. "Creative action in mind." Philosophical Psychology, 24 (4):437 - 461.

Chalmers, D. 2002. "Does Conceivability Entail Possibility?” In Conceivability and Possibility Edited by T. Gendler and J. Hawthorne, 145-200. Oxford: Oxford University Press.

Cope, D. 1991. Computers and Musical Style. Oxford: Oxford University Press. 2001. Virtual Music: Computer Synthesis of Musical Style. Cambridge: MIT Press.

Currie, G. and I. Ravenscroft. 2002. Recreative Minds. Oxford: Oxford University Press.

Finke, R., Ward, T., and Smith, S. 1992. Creative Cognition. Cambridge: MIT Press.

Gaut, B. 2003. "Creativity and Imagination." In The Creation of Art. Edited by B. Gaut and P. Livingston, 148-73. Cambridge: Cambridge University Press. 2009. "Creativity and Skill." In The Idea of Creativity. Edited by M. Krausz, D.

Dutton, and K. Bardsley, 83-103. Leiden, Brill. 2010. "The Philosophy of Creativity." Philosophy Compass, 5 (12):1034-1046.

Gaut, B. and Livingston, P. 2003. "The Creation of Art: Issues and Perspectives." In The Creation of Art. Edited by B. Gaut and P. Livingston, 1-32. Cambridge: Cambridge University Press.

Gendler, T. 2011. "Imagination." in The Stanford Encyclopedia of Philosophy, Edited by E. Zalta. http://plato.stanford.edu/archives/fall2011/entries/imagination/

Guilford, J.P. 1950. “Creativity.” American Psychologist, 5: 444-454.

Hardin, C.L. 1988. Color for Philosophers. Indianapolis: Hackett.

Hausman, C.R. 1984. A Discourse on Novelty and Creation. SUNY Press. 1976. "Introduction: the Creativity Question." In The Creativity Question. Edited by

C.R. Hausman and A. Rothenberg, 3-26. Duke University Press. 1979. "Philosophy of Creativity." Ultimate Reality and Meaning, 2: 143-62.

Hebb, D. 1949. The Organization of Behavior. New York: Wiley.

Hospers, J. 1985. “Artistic Creativity." Journal of Aesthetics and Art Criticism, 43.3: 243-255. 
Hofstadter, D. 2002. "Looking Emmy Straight in the Eye—and Doing My Best Not to Flinch." In Creativity, Cognition, and Knowledge. Edited by T. Dartnall, 67-104. Westport, CT: Praeger.

Ichikawa, J. 2009. “Dreaming and imagination.” Mind and Language. 24 (1):103-121.

Kant, I. 1790/2001. Critique of the Power of Judgment. Edited and translated by E. Matthew and P. Guyer. New York: Cambridge University Press.

Karmiloff-Smith, A. 1990. "Constraints on representational change." Cognition, 34: 57-83. 1992. Beyond Modularity. Cambridge: MIT Press.

Kivy, P. 2001. The Possessor and the Possessed. New Haven: Yale University Press.

Klausen, S. H. 2010. "The notion of creativity revisited: A philosophical perspective on creativity research." Creativity Research Journal, 22(4), 347-360.

Knobe, J. 2012. "Experimental philosophy." In The Oxford Handbook of Philosophy and Cognitive Science. Edited by Eric Margolis, Richard Samuels, and Stephen P. Stich, 528-44. Oxford: Oxford University Press.

Koestler, A. 1964. The Act of Creation. New York: Macmillan.

Kosslyn, S. 1994. Image and Brain. Cambridge, MA: MIT Press.

Kronfeldner, M. E. 2009. “Creativity naturalized.” The Philosophical Quarterly, 59 (237), 577592.

Levinson, J. 2003. "Elster on artistic creativity." The Creation of Art: New Essays in Philosophical Aesthetics, Edited by B. Gaut and P. Livingston, 235-56. Cambridge: Cambridge University Press.

Levorato, M., Nesi, B. and Cacciari, C. 2004. "Reading comprehension and understanding idiomatic expressions: A developmental study." Brain and Language, 91: 303-14.

Levorato, M. and Cacciari, C. 1992. "Children's Comprehension and Production of Idioms: The Role of Context and Familiarity." Journal of Child Language, 19: 415-33. 1995. "The Effects of Different Tasks on the Comprehension and Production of Idioms in Children." Journal of Experimental Child Psychology, 60: 261-83. 2002. "The creation of new figurative expressions: Psycholinguistic evidence on children, adolescents and adults." Journal of Child Language, 29: 127-150.

Lombrozo, T. 2010. "Causal-Explanatory Pluralism: How intentions, functions, and mechanisms influence causal ascriptions." Cognitive Psychology, 61 (4): 303-332.

Lovelace, A. "Notes on Menabra's Sketch of the Analytical Engine Invented by Charles Babbage." In Faster Than Thought. Edited by B.V. Bowden, 362-408. London: Pitman. 
Margolis, E., Samuels, R., and Stich, S., eds. 2012. The Oxford Handbook of Philosophy of Cognitive Science. Oxford: Oxford University Press.

Martindale, C. 1977. "Creativity, consciousness, and cortical arousal." Journal of Altered States of Consciousness, 3: 69-87.

1981. Cognition and Consciousness. Homewood, IL: Dorsey Press.

1990. "Creative Imagination and Neural Activity." In The Psychophysiology of Mental

Imagery. Edited by R. Kunzendorf and A. Sheikh, 89-108. New York: Baywood.

1995. "Creativity and Connectionism." In The Creative Cognition Approach. Edited by S.

Smith, T.B. Ward, and R. Finke, 249-68. Cambridge, MA: MIT Press.

1999. "Biological bases of creativity." In Handbook of creativity. Edited by R. Sternberg,

137-52. Cambridge: Cambridge University Press.

McClelland, J.L., Rumelhart, D.E., and the PDP Research Group. 1986. Parallel Distributed Processing: Explorations in the Microstructure of Cognition. Volume 2: Psychological and Biological Models. Cambridge, MA: MIT Press

Mendolsohn, G. 1976. “Associative and attentional processes in creative performance.” Journal of Personality, 44: 341-69.

Mithen, S. 1996. The Prehistory of the Mind. New York: Thames and Hudson. 1998a. Creativity in human evolution and prehistory. London: Routledge.

1998b. "A creative explosion? Theory of mind, language and the disembodied mind of the Upper Paleolithic." In Human Creativity in Archaeology and Prehistory. Edited by S. Mithen, 97-106. London: Routledge.

2000. "Mind, brain and material culture." In Evolution and the Human Mind. Edited by P.

Carruthers and A. Chamberlain, 207-17. Cambridge: Cambridge University Press.

Nanay, B. 2014. “An experiential account of creativity.” In The Philosophy of Creativity, Edited by E.S. Paul and S.B. Kaufman, 17-38. New York: Oxford University Press.

Nichols, S. and Stich, S. 2000. “A Cognitive Theory of Pretence.' Cognition, 74: 115-47. 2003. Mindreading. Oxford: Oxford University Press.

Noble, W. and Davidson, I. 1996. Human Evolution, Language and Mind. Cambridge:

Cambridge University Press.

Novitz, D. 1999. "Creativity and Constraint." Australasian Journal of Philosophy, 77: 67-82. 2003. "Explanations of creativity." In The Creation of Art. Edited by B. Gaut and P.

Livingston, 174-91. Cambridge University Press: Cambridge.

Paul, E.S., \& Kaufman, S.B., eds. 2014a. The philosophy of creativity. New York, NY: Oxford University Press.

2014b. "Introducing The Philosophy of Creativity." In The philosophy of creativity. Edited by E.S. Paul and S.B. Kaufman, 3-16. New York, NY: Oxford University Press. 
Picciuto, E. and Carruthers, P. 2014. "The origins of creativity." In The Philosophy of Creativity. Edited by E.S. Paul and S.B. Kaufman, 199-223. New York: Oxford University Press.

Plato. 1997. The Complete Works of Plato. Edited by John M. Cooper and D. S. Hutchinson. Indianapolis: Hackett Publishing.

Prinz, J. 2008. "Empirical and Experimental Philosophy." In Experimental Philosophy. Edited by Joshua Knobe and Shaun Nichols, 189-208. New York: Oxford University Press.

Prinz, J. and Barsalou, L. 2002. "Acquisition and Productivity in Perceptual Symbol Systems: An Account of Mundane Creativity. In Creativity, Cognition, and Knowledge. Edited by T. Dartnall, 105-38. Westport, CT: Praeger.

Rumelhart, D.E., McClelland J.L. and the PDP Research Group. 1986). Parallel Distributed Processing: Explorations in the Microstructure of Cognition. Volume 1: Foundations.

Cambridge, MA: MIT Press

Schopenhauer, A. 1969. The World as Will and Representation, Volumes I and II. Trans. E. F. J. Payne. New York: Dover.

Searle, J. 1980. "Minds, brains, and programs." Behavioral and Brain Sciences, 3 (3):417-57.

Simonton, D. 1999. Origins of Genius. Oxford: Oxford University Press.

Smith, S. and Blankenship, S. 1989. "Incubation effects." Bulletin of the Psychonomic Society 27: $311-14$.

1991. "Incubation and the persistence of fixation in problem solving." American Journal of Psychology, 104: 61-87.

Sperber, D. 1996. Explaining Culture. Oxford: Blackwell.

Sternberg, R. J., \& Lubart, T. I. 1999. "The concept of creativity: Prospects and paradigms." Handbook of creativity. Edited by R. Sternberg, 3-15. Cambridge: Cambridge University Press.

Stokes, D. 2007. "Incubated cognition and creativity." Journal of Consciousness Studies, 14: 83100 .

2008 "A metaphysics of creativity." In New Waves in Aesthetics. Edited by K. Stock and K. Thomson Jones, 105-24. Hampshire and New York: Palgrave Macmillan. 2011. "Minimally creative thought." Metaphilosophy, 42(5): 658-81. 2014. "The role of imagination in creativity." In The Philosophy of Creativity. Edited by E.S. Paul and S.B. Kaufman, 157-84. New York: Oxford University Press.

Stokes, D. and Bird, J. 2008. "Evolutionary robotics and creative constraints." In Beyond the Brain: Embodied, Situated, and Distributed Cognition. Edited by B. Hardy-Vallée and N. Payette, 227-45. Newcastle: Cambridge Scholars Publishing. 
Stokes, P. D. 2001. "Variability, constraints, and creativity: Shedding light on Claude Monet." American Psychologist, 56(4), 355-59.

2005. Creativity from constraints: The psychology of breakthrough. New York: Springer Publishing Company.

2008. "Creativity from Constraints: What can we learn from Motherwell? from Modrian? from Klee?" The Journal of Creative Behavior, 42(4), 223-236.

2007. "Using constraints to generate and sustain novelty." Psychology of Aesthetics, Creativity, and the Arts, 1(2): 107-13.

Stokes, P. D., \& Harrison, H. M. 2002. "Constraints have different concurrent effects and aftereffects on variability." Journal of Experimental Psychology: General, 131(4), 552-66.

Torreano, L., Cacciari, C. and Glucksberg, S. 2005. "When Dogs Can Fly: Level of Abstraction as a Cue to Metaphorical Use of Verbs." Metaphor and Symbol, 20: 259-74.

Wallas, G. 1926. The Art of Thought. New York: Harcourt, Brace, and World.

Weisberg, R. 1986. Creativity: Genius and Other Myths. New York: W.H. Freeman.

Ward, T.B. 1994. "Structured Imagination: The role of category structure in exemplar generation." Cognitive Psychology, 27: 1-40.

Ward, T., Smith, S., and Finke, R. 1999. "Creative cognition.” In Handbook of

Creativity. Edited by R. Sternberg, 189-212. Cambridge: Cambridge University Press.

Woodworth, R. and Schlosberg, H. 1954. Experimental Psychology. New York: Holt, Rinehart, and Winston.

Wynn, T. 2000. "Symmetry and the evolution of the modular linguistic mind." In Evolution and the Human Mind. Edited by P. Carruthers and A. Chamberlain, 113-39. Cambridge: Cambridge University Press.

Yablo, S. 1993. "Is Conceivability a Guide to Possibility?" Philosophy and Phenomenological Research, 53:1-42.

Young, J.Z. 1951. "Ferrier Lectures" Proceedings of the Royal Society of London, B, 139:18. 
${ }^{1}$ This includes two recently published volumes of new papers (Gaut and Livingston 2003; Paul and Kaufman 2014a), survey pieces (Boden 2005; Gaut 2010), an essay prize focused on the topic (Philosophical Quarterly 2008), and a number of peer-reviewed journal papers (many of them to be cited and discussed below).

${ }^{2}$ Guilford 1950. Also see Paul and Kaufman 2014b for discussion.

${ }^{3}$ For example, there are a number of specialty journals in existence: Psychology of Aesthetics, Creativity and the Arts; Creativity Research Journal; Journal of Creative Behavior; International Journal of Creativity and Problem Solving; Digital Creativity. It is also probably worth noting that even if creativity has and does enjoy substantial attention in the cognitive sciences (broadly construed), it still receives comparatively less attention than various other mental and behavioral phenomena (some of them arguably much less important than creativity).

${ }^{4}$ The present volume as a whole exemplifies this trend. For reflections on this movement, see Jesse Prinz (2008); Margolis, Samuels, and Stich (2012). The integration between philosophy and science is especially pronounced in research on such topics as color perception (beginning with Hardin 1988; more recently see Byrne and Hilbert 2003) and causal cognition (e.g., Lombrozo 2010).

${ }^{5}$ This is in keeping with the definition given by one of the main founders of field, Joshua Knobe: "experimental philosophy seeks to examine the phenomena that have been traditionally associated with philosophy using the methods that have more recently been developed within cognitive science" (Knobe 2012, p.1). See also Knobe, this volume.

${ }^{6}$ In one often cited formulation: "Creativity is the ability to produce work that is both novel (i.e., original, unexpected) and appropriate (i.e., useful, adaptive concerning task constraints)" (Sternberg and Lubart, 1999, p. 3). This standard definition of creativity was anticipated by Immanuel Kant, in a way, when he described the (creative) 'genius' as someone capable of producing things that are not only original - for "there can be original nonsense" but also, as he put it, "exemplary" (Kant 1790/2001: 43-50). For philosophical discussion of the standard definition, see Klausen (2010). For a challenge to inclusion of a value condition, see D. Stokes 2008, 2011. Stokes argues that while creativity is itself a value, inclusion of value as a satisfaction condition is insufficiently motivated because uninformative. By analogy, countless artefactual kinds - bicycle pumps, elevators, smart phones--are useful (and so thereby valuable), but one would not include utility (or "being valuable") in a conceptual clarification or definition of such objects, simply because this offers no information regarding why an object of that kind is useful.

${ }^{7}$ As Boden sometimes abbreviates them, and as they will sometimes be abbreviated below, $h$-creativity (or novelty) and p-creativity (or novelty).

${ }^{8}$ Boden 1999; 2004; 2014

${ }^{9}$ Gaut 2009; 2011; Stokes 2011.

${ }^{10}$ Novitz 1999, 2003

${ }^{11}$ The most relevant Platonic dialogues are the Ion and the Phaedrus (Plato, $4^{\text {th }}$ c. BCE/1997). For discussion, see Asmis (1992)

12 Arthur Schopenhauer 1969 Vol I: 184-194 and 1969 Vol II: 376-402.

${ }^{13}$ See Koestler, 1964; Martindale, 1977; 1981; 1990; 1995; 1999; Mendelsohn, 1976; Wallas 1926.

${ }^{14}$ See Hospers 1985.

${ }^{15}$ For general examples of re-use explanations of mental and/or neural processes, see Anderson 2010 and Bergeron 2007.

${ }^{16}$ The Cortical Arousal Theory is another example of a special mechanism explanation. See Martindale 1977, 1981, 1995, 1999.

${ }^{17}$ See Carruthers $(2007 ; 2011)$, who adapts the Geneplore model and argues that the generation stage of creativity involves the rehearsal of action-schemata (or motor plans) rather than conceptual or propositional representations. A more extreme, indeed deflationary, version of a re-use explanation is Robert Weisberg's Incremental Problem Solving Model (Weisberg 1986). Weisberg argues that many alleged features of creativity are mere folk myths, and that all actual features of the phenomenon can be explained by appeal to intelligence, skill mastery, problem-specific knowledge, and persistent problem solving attempts.

${ }^{18}$ But see discussion of Carruthers 2002 in III.2 below for defense of this kind of story.

${ }^{19}$ On fixation and problem solving, see also Woodworth and Schlosberg 1954; Smith et al 1995.

${ }^{20}$ Relatedly, see Young 1951; Rosenblatt 1958; McClelland et al 1986; Rumelhart et al 1986

${ }^{21}$ When I read a novel or watch a film, one thing I am doing is imagining in a way that follows the narrative guide. This can be cognitively and emotionally rich, but it is not creative in the relevant sense. Instead, it is what Currie and Ravenscroft (2002) call re-creative imagination. The present interest, then, is in the creative imagination

${ }^{22}$ The strength of Gaut's claim here is elusive. Gaut explicitly resists the claim that there are any necessary relations between imagination and creativity. There are many non-creative uses of the imagination (reading a novel or 
watching a film) and there are non-imaginative instances of creativity (Gaut identifies a-ha moments of insight as possible examples). However, Gaut also claims to have established a "constitutive connection" between imagination and creativity, since imagination is suited "of its nature" to serve as a vehicle for creativity. The latter is presumably a claim about mental state types, but it is hard to square with the denial of any necessary relations between those types. The charitable interpretation may be this: the intrinsic natures of imagination and creativity (how these types are constituted, one might say) are such that the first especially well-serves, but is neither necessary nor sufficient for, achievement of the second kind.

${ }^{23}$ For other work on mundane or minimal creativity: see Barsalou and Prinz 1997; Prinz and Barsalou 2002; Nanay 2014; D. Stokes 2008, 2011.

${ }^{24}$ For examples of cross-category drawing experiments, see Karmiloff-Smith 1990, 1992; Cacciari et. al 1997; Ward 1994, 1995). For relevant examples of research on figurative language learning and use, see Levorato 2004; Levorato and Cacciari 1992, 1995, 2002; Toreano et al. 2005;

${ }^{25}$ See Stich and Nichols 2000, 2003 for a cognitive theory of imagination. On imagination and modal epistemology, see Yablo 1993; Chalmers 2002, and Gendler and Hawthorne 2002 for a collection. For a useful resource on the imagination see Gendler 2011.

${ }^{26}$ For a useful analogue, see Ichikawa's (2009) analysis of the relation between dreaming and imagination.

${ }^{27}$ This is sometimes called the "creativity explosion" (Mithen 1996; 1998a).

${ }^{28}$ In particular, Carruthers criticizes both pure language-base explanations (Noble and Davidson 1996) and language-culture hybrid explanations (Bickerton 1995; Sperber 1996; Mithen 1998b, 2000).

${ }^{29}$ Regarding imagery and vision, Carruthers cites the findings in vision science by Kosslyn 1994 and the cognitive archaeological research of Wynn (2000). Gaut (2009) worries about the species-specificity of Carruthers' thesis, noting that many non-human animals appear to engage in pretend play. And second, the creativity explosion timeline is controversial (and indeed Carruthers 2006 abandons this as a criterion for a successful explanation). ${ }^{30}$ The historical, theoretical precedent for this kind of skepticism is the Lady Lovelace objection (Lovelace 1953).

${ }^{31}$ This maps on to a familiar distinction between "Weak AI" and "Strong AI". Even Searle (1980), who made the distinction, accepts that the first is possible while consistently denying the possibility of the second. See also Boden 2014.

${ }^{32}$ Although not a controlled experimental context, Hofstadter reports that approximately $1 / 3$ of a listening audience, ranging from musical novice to expert, fail to distinguish the genuine Bach piece from Emmy's Bach piece.

${ }^{33}$ Other theorists have argued that creativity is compatible with, and even enhanced by constraints. These include both psychologists (e.g. Stokes, P.D., 2001; 2005; 2007; 2008; Stokes, P. D., \& Harrison, H. M., 2002) and philosophers (e.g. Elster, J., 2000, ch. 3). For responses to Elster, see Osborne (2011) and Levinson (2003). 